\title{
Geodetic, geophysical and geographical methods in landslide investigation: Luar case study
}

\author{
Vladislav Zaalishvili ${ }^{1,2^{*}}$, Khisa Chotchaev $^{1}$, Dmitry Melkov ${ }^{1}$, Olga Burdzieva $^{1}$, Boris \\ Dzeranov ${ }^{1}$, Aleksandr Kanukov ${ }^{1}$, Inga Archireeva ${ }^{1}$, Akhsarbek Gabaraev ${ }^{1}$, and Laura \\ Dzobelova $^{1}$ \\ ${ }^{1}$ Geophysical Institute, Vladikavkaz Scientific Center, Russian Academy of Sciences, 362002, \\ Markova Street, 93a, Vladikavkaz, Russian Federation \\ ${ }^{2}$ North Ossetian State University after K.L. Khetagurov, 362025, Vatutina Street, 44-46, Vladikavkaz, \\ North Ossetia - Alania, Russian Federation
}

\begin{abstract}
According to the variety and the intensity of dangerous natural processes occurence, the Greater Caucasus can serve as a natural laboratory, where geodynamic processes of a different order proceed continuously. One of the most destructive natural processes are the landslides. A reference object in this regard is the Luar landslide, which has included all the extreme features of landslide structures known in the Central Caucasus, but has not revealed the secrets of its static state, the determination of which is the most important task of the scientific research. An active landslide formed as a result of anthropogenic activity (slope cutting ) is also considered. The mentioned objects were examined by the geodetic and geophysical methods. Appropriate monitoring systems have been created.
\end{abstract}

\section{Introduction}

Natural processes of an endogenous and exogenous nature, representing the varying degry of hazard for the population, are a commonplace of the planet active life. Landslides are one of the most destructive natural processes. They are formed on the shallow sections of the steep slopes of the large mountain rivers and their tributaries, where the high erosion potential is determined by the outcrops of bedrock of relatively low strength of sandy-clay composition such as siltstones, mudstones, marls, soft limestones, dislocated dolomites and other half-rocks in combination with erosional pattern extended several $\mathrm{km} / \mathrm{km}^{2}$ and local erosion bases of 1000-1500 m.

According to the variety and intensity of dangerous natural processes' manifestations, the Greater Caucasus can serve as a natural laboratory where geodynamic processes of a seismotectonic nature continuously occur on a continental scale, due to the collision of the Scythian plate and southern microplates supported by the Arabian plate, as well as on a regional scale, caused by the activation of seismicity in the zones of deep faults. High

* Corresponding author: cgi ras@mail.ru 
seismicity, caused by the active deep geodynamic processes and stresses in the zone of plates ' collision, affects a strongly dissected relief and activates many hazardous exogenous processes (mudflows, landslides, avalanches, landfalls) [1,2].

One of such unstable structures, widely developed in the mountainous part of the Greater Caucasus, are landslides, which are long-term forming geological objects, the development dynamics, morphological and structural-lithological features, the spatial characteristics and static state of which can be studied in detail and it will be possible to give a reasonable conclusion for making design decisions by the executive authorities.

The most hazardous for the designed and operating national economic facilities (Mizur enriching plant, a number of operating mines in the gorges with mudflow dangerous slopes, Transkam, Zaramag hydroelectric power plant, the first stage of the Mamison tourism cluster) were studied in the previous years during the above-mentioned design decisions and during the industrial operation of the facilities. As a result, it was found that the causes and mechanisms of landslide movement are quite diverse and are associated with both gravitational and climatic, as well as with seismotectonic processes occurring in the general cycle of neotectonic upward movements of the Greater Caucasus.

The Luar landslide seems to be the reference object in this regard, which has included all the extreme features of landslide structures known in the Central Caucasus, but has not revealed the secrets of its static state, the determination of which is the most important task of the scientific research.

The Luar landslide hangs dangerously over one of the rapid water flows of the North Ossetia-Alania - Ardon River - and is considered as a potential threat to a number of settlements and the Federal Highway Transkam.

\section{Geodetic monitoring}

Measurement of the geometric characteristics of the earth's surface is a critical phase of any major civil engineering construction. Monitoring of the structures' deformation and displacements of the earth's surface during landslides can be carried out using various types of systems and methods [3]. These methods and tools can be classified as remote sounding methods or satellite, photogrammetric and geodetic methods [4-11]. The choice of instruments and measurement methods or the creation of a special monitoring system depends on various types of deformation, which will affect the method of stability analysis and, consequently, the entire deformation monitoring system [3, 12-22].

Satellite images in the optical region with a high spatial resolution are used to map the landslide inventories. Satellite data is used in addition to the aerial photography or as an equivalent if there are no recent aerial photographs. In addition, for regional and national hazard zoning, satellite imagery is a more economical database. Another advantage of satellite remote sounding is the possibility of the repeated observations, which leads to a more frequent updating of information about landslide characteristics than in traditional data sources. Only very large landslides can be identified directly on a small satellite imagery. The value of satellite imagery lies in the fact that the susceptibility of the area to the landslides can be determined indirectly by some signs which can be identified at these scales. Satellite images show regional physiography, the geological structure and most of the landforms, as well as the practice of land use and the distribution of vegetation. A similar method is suitable for the preliminary analysis of the large areas.

Another important application of Earth observation data is the creation of digital elevation models (DEM), which are the basic information for slope characterization and numerical modeling [3]. Models of the large areas can be obtained on the basis of satellite data, for example GTOPO30, with a resolution of $1 \mathrm{~km}$. For local areas, a scan can be 
performed with a resolution of up to a fraction of a meter; it all depends on the speed of the equipment used and the feasibility of the task being solved [15].

The use of robotic tachymeters gives the possibility of the collecting three-dimensional location information for automatic monitoring of deformation. They can automatically measure angles and distances. Modern tachymeters can measure angles with an accuracy of up to 1 second and distances with an accuracy of $\pm 1 \mathrm{~mm}$. At the distances up to $3500 \mathrm{~m}$ (accuracy decreases with distance). Tachymeters allow one to measure multiple points with prismatic targets on a controlled surface for a short period of time. Using Automatic Target Recognition (ATR) technology, it is possible to find each prism and determine its center to ensure the accuracy of targeting. Such technologies are ideal for precise applications in cases when the error absence is desired. However, the use of a sufficient number of prisms for permanent installation on a slope is not economically feasible; prisms are also accurate optical devices that can easily be damaged not only as a result of vandalism, but also under the influence of natural factors.

When moving and installing the prism manually, the advantage of using tachymeter, which is possible to realize measurements at a distance, is lost. We have investigated various reflective surfaces to ensure a stable measurement at large distance for the Luar landslide. The use of a robotic total station allows you to aim at the reflectors automatically, according to the results of the previous measurements. The created system requires the participation of the operator to accurately point the reflector to the crosshair, however, it significantly reduces the work of regular geodetic monitoring. The disadvantage of tachymeter survey using is the necessity for line of sight to measurements realization. However, in all cases, for all objects we were able to select survey points covering the most important areas for monitoring. In extreme cases, GPS technology can be used [20].

A monitoring system of the Luar landslide is presented in Fig. 1 as an example. Survey is conducted from the opposite slope. The distance to distant reflectors is more than $1 \mathrm{~km}$. An example of scanning a slope of a small landslide (Fiagdon tailing dump) is shown in Fig. 1.

\section{Geophysical methods}

The geological characteristics of the Luar landslide is gathered from the stock materials of a specialized geological exploration expedition (SOGRE, later the "Sevosgeologorazvedka") of the North Caucasian Territorial Geological Administration (NCTGA) and from the works performed under a grant in 2019. The data of 8 boreholes were used to compile geological and geophysical sections together with the data of 29 points of vertical electrical sounding, performed on spans $\mathrm{AB} / 2=325 \mathrm{~m}$. To study the structure of the upper part of the landslide, three profiles of geolocation sounding by the OKO-2 Georadar at $150 \mathrm{MHz}$ frequencies were performed (Fig. 2).

Seismic surveys were conducted (Fig. 3). During seismic observations vertical (to calculate the propagation velocity of a primary wave) and horizontal (to calculate the propagation velocity of a shear wave) components of the elastic wave in the soil were recorded. A system of single and multiple observation and recording of oncoming traveltime curves of primary and shear waves was used. 
a)

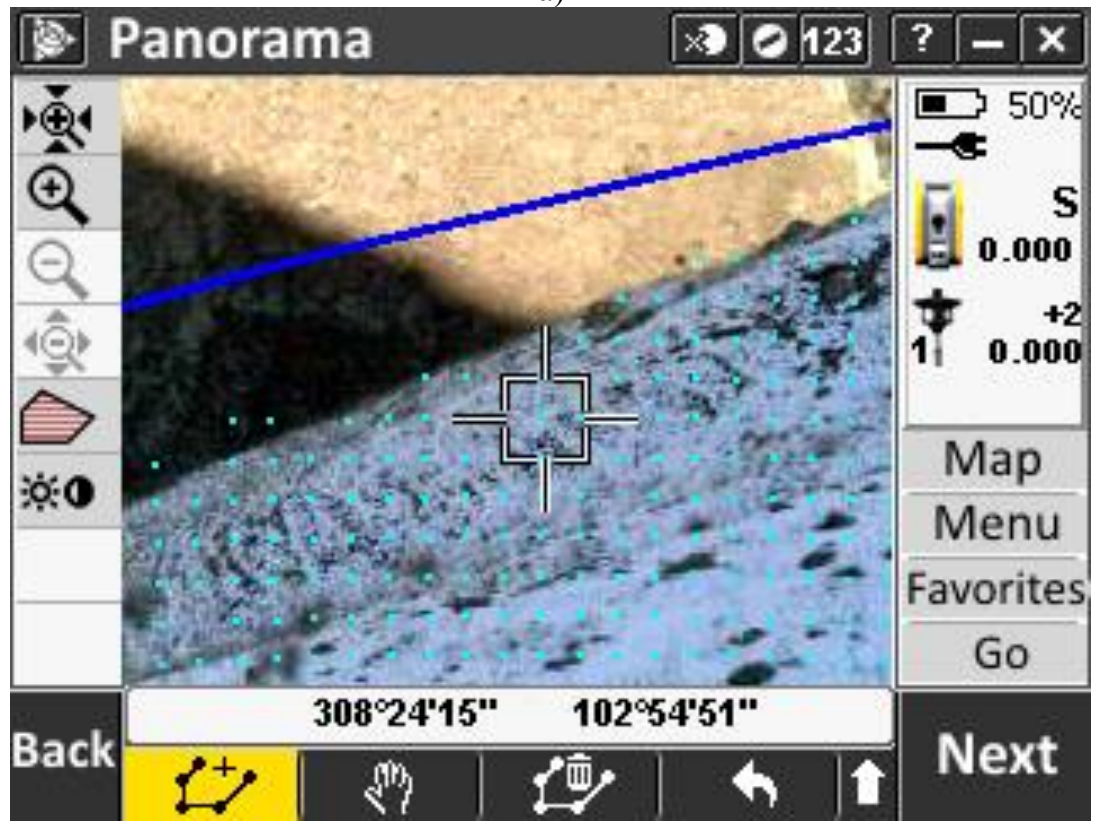

b)

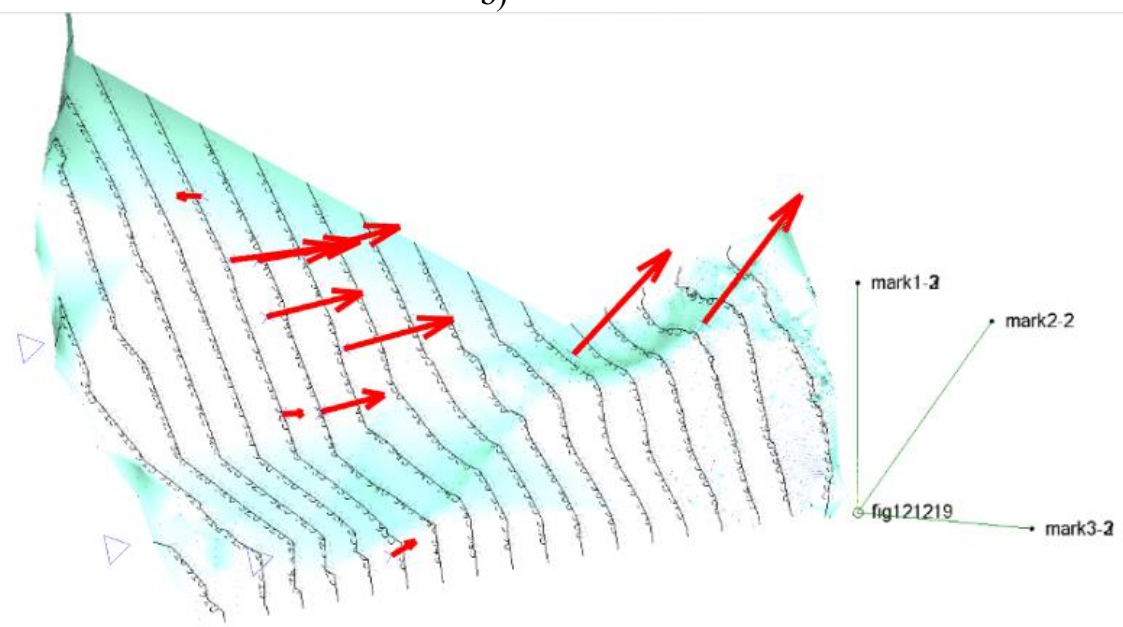

L.

Fig. 1. A fragment of the Fiagdon landslide during scanning (a) and a digital surface model calculated from the point cloud (b). The arrows indicate the offsets of the reference points.

Parameters and main technical characteristics of the used digital seismic equipment Lakkolit X-M2 (the number of simultaneously recorded channels is 24, the range of recorded frequencies is 5-4000 Hz; ADC resolution is 24; Seismic receivers are SG-20 and SV-20.).

The main vibration source of primary and shear waves during registration of the vertical and horizontal components of vibration respectively was: a hammer set with a load of 400 $\mathrm{kg}$, a sledgehammer with a weight of $8 \mathrm{~kg}$ and a manual tamper weighing $17 \mathrm{~kg}$. Data was recorded in 10-fold discrete registration mode for subsequent summation when using a 
tamper and sledgehammer and in a single recording mode when using a hammer set. To obtain a 48-channel record, the seismic streamer was moved and elastic vibrations were regenerated, followed by the combination of two 24-channel records into one 48-channel.

The shear waves were generated by horizontal impacts on the wall of the test pit with a manual tamper, which allows identifying discrete impacts by the accuracy of their execution, in comparison with vibrations during impacts with a sledgehammer. The horizontal direction of the impact was across the seismic line, i.e. parallel to the vibratory system of horizontal geophones. To determine the anisotropic properties of soils, depending on the arrival direction of the wave, shear waves were generated and recorded in opposite directions.

To eliminate such effects, it is necessary to filter the seismic record at different frequency intervals from the bottom and the top, using a wide selection of filters and amplification stages. 
a)

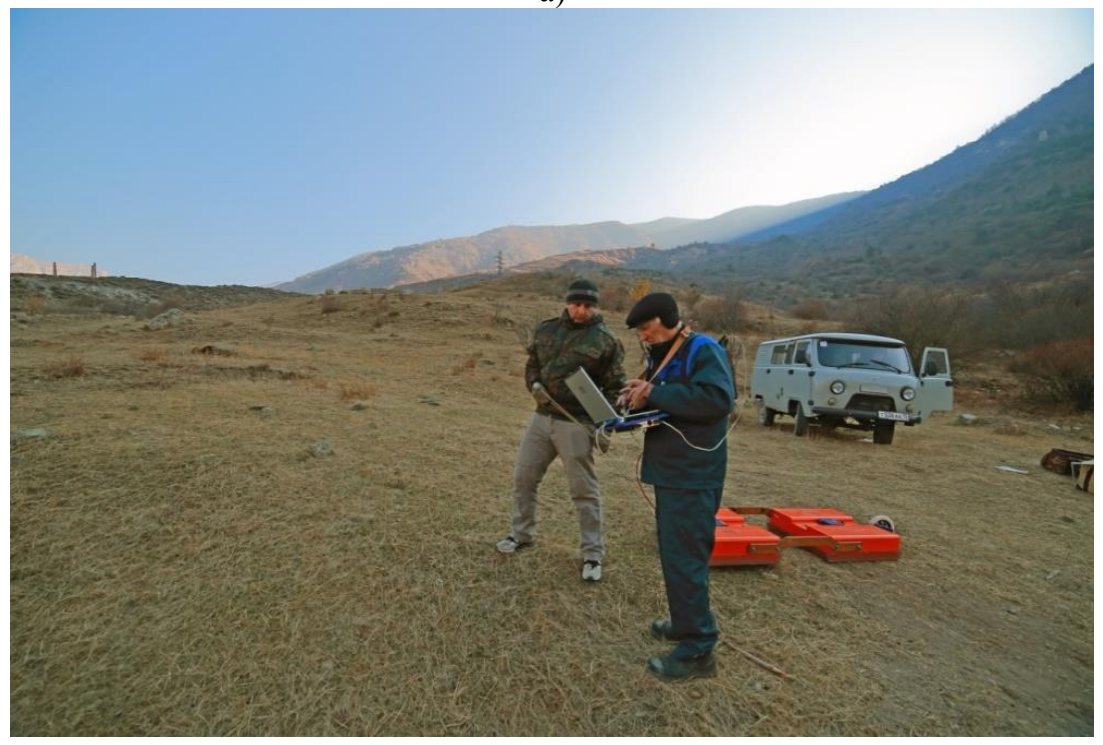

b)

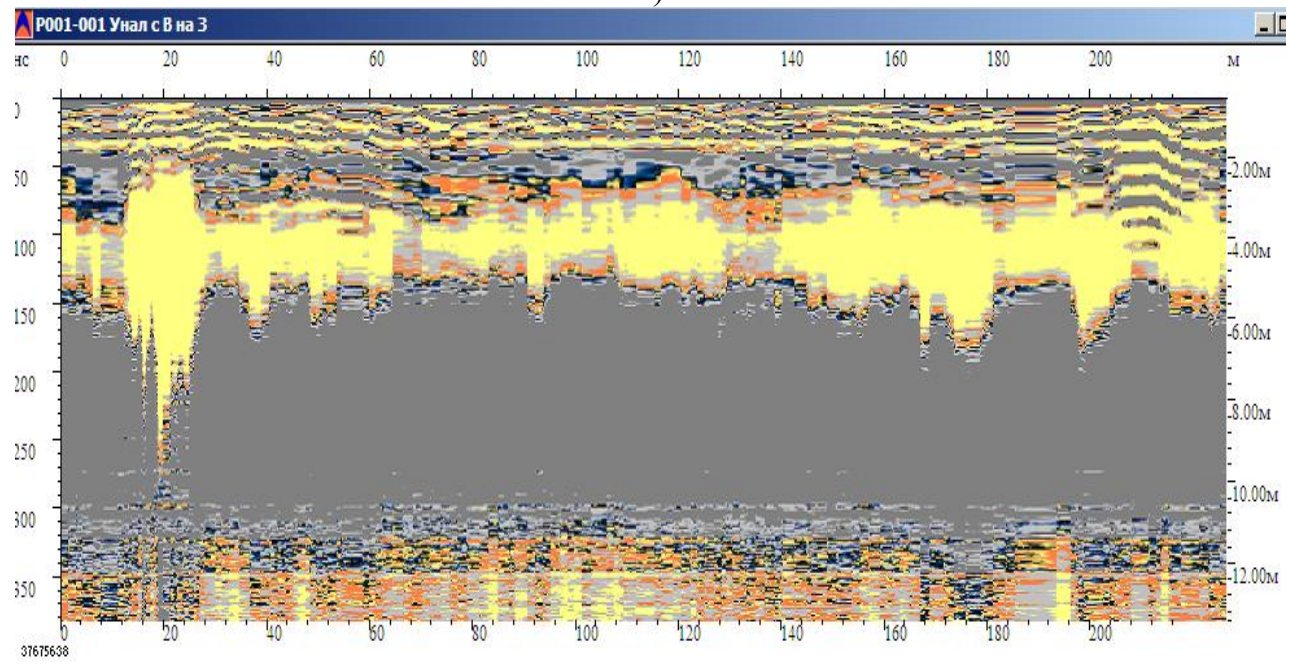

Fig. 2. Georadar sounding of one of the sections of the Luar landslide (a) and the resulting wave pattern of the upper part of the section (b).

The main stage of processing seismic data is the identification of a refracted wave, the formation of which is possible in media satisfying the condition V2>V1, where V2 is the elastic wave velocity in the underlying layer, and V1 is the elastic wave velocity in the overlapping layer. The appearance moment of the refracted wave corresponds to the achievement of the critical angle of reflection, when the reflected wave is divided into the actually reflected and refracted waves. Refracted wave runs along the surface of the highvelocity underlying layer, which is marked on the hodograph of the direct wave by bifurcation of the wave into a direct and refracted one. With the generation of the refracted wave, then it first reaches the geophones of the spaced seismic streamer (cable with sensors). Reflected wave during engineering-geological surveys, as a rule, is not 
considered, since at low soil powers it is practically impossible to separate the direct and reflected waves.

a)

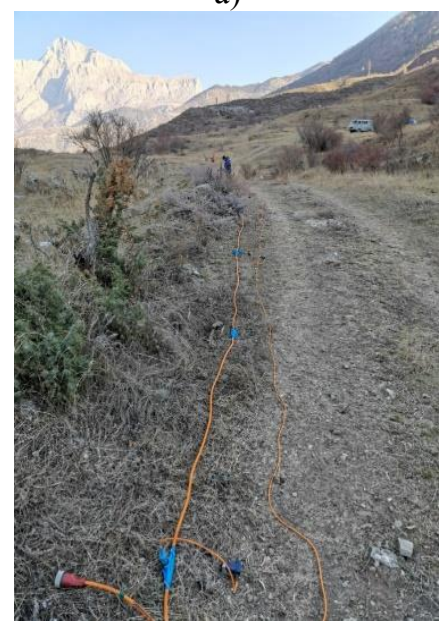

b)

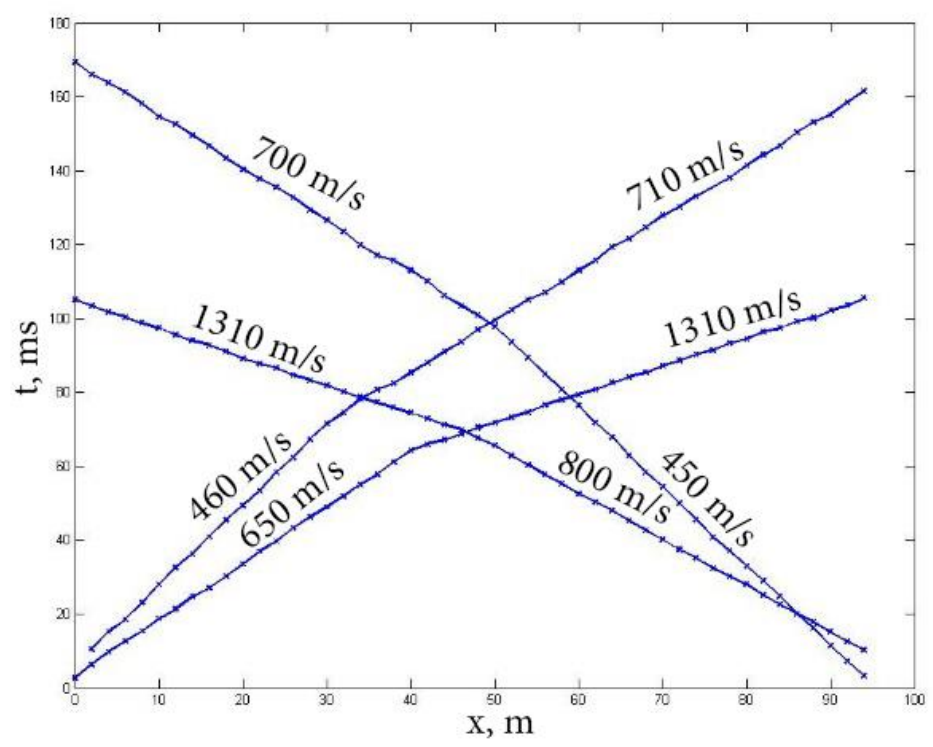

Fig. 3. Laying of seismic cable in the studied area (a) and the obtained hodographs (b).

The identified direct and refracted waves are represented in the form of hodographs reflecting the dependence of the arrival time of an elastic direct or refracted wave on the distance of geophones to the vibration point. The characteristic knees of the hodographs were used to determine the refracting boundaries of soils of different compositions. The examples of hodographs are shown in Fig.3b. Based on typical seismic surveys, using the ZZ, YY +, YY- schemes, the propagation velocities of primary and shear waves were determined. 
The mail volume of the processing and interpretation of seismograms was carried out on the basis of computer programs RadexProPlus version 3.75. To identify primary and shear waves, the phase inversion phenomenon and other features were used.

\section{Geographic methods}

The descriptive method is an auxiliary in collecting field or literary factual materials. The dialectical method considers the study of all phenomena, processes in their development (for example, landscape) and allows to predict trends in the development of their transition from one state to another. One of the oldest research methods in geography is the method of comparison. The complexes or individual components of the complexes can be compared: the forms of relief, climatic indicators, soils, etc. The stationary method is used to study phenomena that rapidly change in time: temperature, direction and speed of the wind, humidity, runoff of surface waters, as well as in the study of changes that occur in complexes by seasons, years, etc. The expeditionary method allows exploring phenomena and processes that vary in space, slowly change in time. Cartographic also refers to the relatively old methods, but nowadays it has a very pronounced tendency to differentiated development of specialized and complex maps. The special significance of this method is to identify the patterns of spatial distribution of geographic objects, phenomena and processes, their interconnections and dependencies in development. Air photography method is a progressive method in understanding the structure, features of the development of the geographical environment and its landscapes [23-28]. The space method is the latest method of studying geographical phenomena. Here, photographs cover more extensive areas and can be obtained quickly for any territory on the earth's surface. The availability of satellite images has greatly simplified the exploration of the Luar landslide. At the same time, elements of the typological method were used that were closely related to mapping, the identification of areas that correspond to certain classification grades, and mapping the boundaries of the types of places or complexes, for example, in accordance with types or forms of relief, etc. The method of zoning appeared relatively long ago. The leading role of this or that factor (geological, geomorphological, etc.) distinguishes the following subdivisions. The basis for zoning can be a landscape map of surveying the simplest complexes - large-scale and medium-scale, for shooting more complex, higher taxonomic units - small-scale. The complex or landscape method is used when examining a territory of complex composition. The most of the approaches given above, including historical ones were actually used in present work [4, 8, 17, 21, 23, 29-33].

The geological map of the Luar landslide that was compiled on the basis of all the data obtained is presented in Fig. 4. 


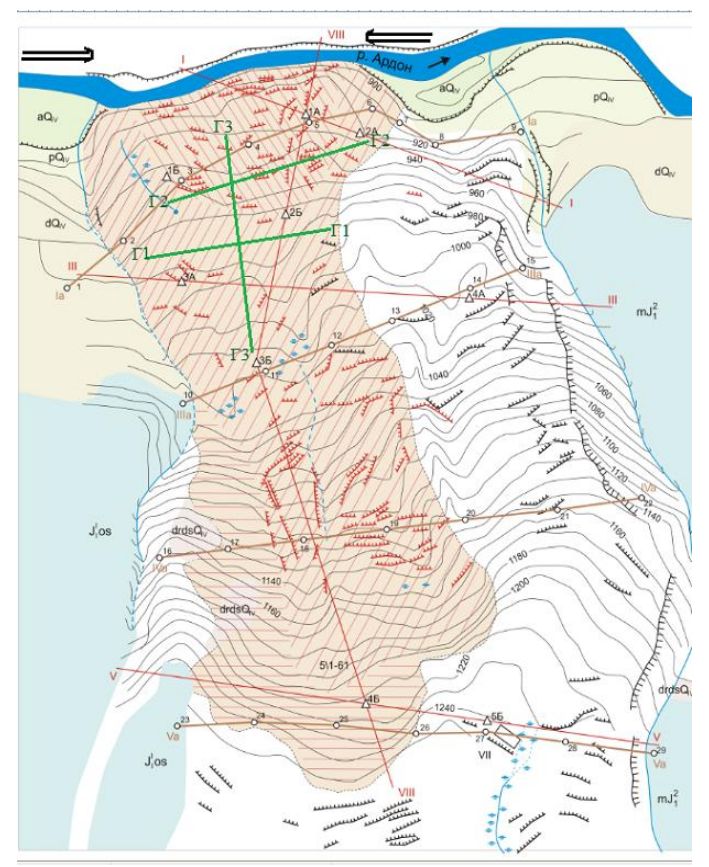

Fig. 4. Geological map of Luar landslide.

\section{Conclusions}

Remote sensing data can provide important information for mapping landslides. Some methods, such as the use of new very high resolution optical satellite data for monitoring landslide inventories and hazard assessments, need further development. Powerful InSAR tools that provide accurate topography and motion maps and thus can make a significant contribution to assessing and mitigating the risk of landslides, but can be too expensive.

Ground-based laser scanning technologies are faster and more accurate ways to obtain dense three-dimensional sets of points (point clouds). For structural monitoring applications, laser scanning can be considered advantageous in comparison with geodetic methods (for example, GPS), which can perceive deformation only in a limited number of points, while the scanner can measure the deformation surface. Only a few of the many monitoring methods provide an accurate three-dimensional indication of the displacement vectors of the control points on the surface of the slip area. GPS is a new technology that can be used to create tight three-dimensional time series to display the position and speed of the deforming mass. Permanent regional-level GPS networks, such as those used to monitor tectonic movement, can provide dense and accurate time series of three-dimensional deformation data with high installation and maintenance costs. Occasional GPS monitoring methods may be a cheaper alternative, but they lead to a decrease in accuracy and a decrease in the time density of coordinate time series.

The use of robotic tachymeters allows to increase the number of ground points (benchmarks) while monitoring remotely.

Geodetic methods allow only the surface monitoring. However, the processes causing the movement of masses can occur at depth, without noticeable surface changes. Therefore, geophysical methods such as georadar sounding, seismic exploration, and electrical exploration can be used for monitoring. 
The research was supported by Russian Science Foundation (Project No. 19-47-02010 RSF -DST (2018):" Natural hazards and monitoring for mountain territories in Russia and India".

\section{References}

1. G. Ganapathy, V. Zaalishvili, et al., Geology and Geophysics of Russian South 8 (2018) doi: 10.23671/VNC.2018.3.16552

2. V. Svalova, V. Zaalishvili, et al., Geology and Geophysics of Russian South 9 (2019) doi: 10.23671/VNC.2019.2.31981

3. P. Savvaidis, From Stars to Earth and Culture In honor of the memory of Professor Alexandros Tsioumis, 242-258 (2003)

4. A. Bichler, P. Bobrowsky, et al., Landslides 1 (1), 29-40 (2004) doi:10.1007/s10346003-0008-7

5. G. Bievre, D. Jongmans, T. Winiarski, V. Zumbo, Hydrological Processes 26 (14), 2128-2142 (2012) doi:10.1002/hyp.7986

6. V. Bogoslovsky, A. Ogilvy, Geophysics 42 (3), 562-571 (1977) doi:10.1190/1.1440727

7. E. Bruckl, F. Brunner, K. Kraus, Engineering Geology 88 (3-4), 149-159 (2006) doi:10.1016/j.enggeo.2006.09.004

8. J. Caris, T. Vanasch, Engineering Geology 31 (3-4), 249 (1991)

9. B. Casson, C. Delacourt, P. Allemand, Natural Hazards and Earth System Sciences 5 (3), 425-437 (2005) doi:10.5194/nhess-5-425-2005

10. J. Chambers, P. Wilkinson, et al., Geomorphology 125 (4), 472-484 (2011) doi:10.1016/j.geomorph.2010.09.017

11. W. Dade, H. Huppert, Geology 26 (9), 803-806 (1998).

12. F. De Blasio, A. Elverhoi, et al., Marine and Petroleum Geology 22 (1-2), 179-186 (2005) doi:10.1016/j.marpetgeo.2004.10.014

13. P. De Vita, D. Agrello, F. Ambrosino, Journal of Applied Geophysics 59 (2), 126-139 (2006) doi:10.1016/j.jappgeo.2005.09.001

14. A. Godio, C. Strobbia, G. De Bacco, Engineering Geology 83 (1-3), 273-286 (2006) doi:10.1016/j.enggeo.2005.06.034

15. F. Guzzetti, M. Manunta, et al., Pure and Applied Geophysics 166 (8-9), 1425-1459 (2009) doi:10.1007/s00024-009-0491-4

16. H. Havenith, A. Strom, et al., Natural Hazards and Earth System Sciences 3(1-2), 135 149 (2003) doi:10.5194/nhess-3-135-2003

17. D. Jongmans, G. Bievre, F. Renalier, S. Schwartz, N. Beaurez, Y. Orengo, Engineering Geology 109 (1-2), 45-56 (2009) doi:10.1016/j.enggeo.2008.10.005

18. D. Jongmans, S. Garambois, Bulletin De La SocieteGeologique De France 178 (2), 101-112 (2007) doi:10.2113/gssgfbull.178.2.101

19. G. Li, A. J. West, et al., Geochemistry Geophysics Geosystems 15 (4), 833-844 (2014) doi: $10.1002 / 2013 \mathrm{gc} 005067$

20. J. Malet, O. Maquaire, E. Calais, Geomorphology 43 (1-2), 33-54 (2002) doi:10.1016/s0169-555x(01)00098-8

21. H. Mauritsch, W. Seiberl, et al., Engineering Geology 56 (3-4), 373-388 (2000) doi:10.1016/s0013-7952(99)00120-9

22. D. McCann, A. Forster, Engineering Geology 29 (1), 59-78 (1990) doi:10.1016/00137952(90)90082-c 
23. O. Meric, S. Garambois, et al., Canadian Geotechnical Journal 42 (4), 1105-1115 (2005) doi:10.1139/t05-034

24. O. Meric, S. Garambois, et al., Bulletin De La SocieteGeologique De France 178 (2), 137-148 (2007) doi:10.2113/gssgfbull.178.2.137

25. V. Naudet, M. Lazzari, et al., Engineering Geology 98 (3-4), 156-167 (2008) doi:10.1016/j.enggeo.2008.02.008

26. A. Perrone, V. Lapenna, S. Piscitelli, Earth-Science Reviews 135, 65-82 (2014) doi:10.1016/j.earscirev.2014.04.002

27. B. Pitman, C. Nichita, et al., Physics of Fluids 15 (12), 3638-3646 (2003) doi:10.1063/1.1614253

28. E. Pitman, C. Nichita, et al., Discrete and Continuous Dynamical Systems-Series B 3 (4), 589-599 (2003)

29. O. Sass, R. Bell, T. Glade, Geomorphology 93 (1-2), 89-103 (2008) doi:10.1016/j.geomorph.2006.12.019

30. L. Schrott, O. Sass, Geomorphology $93 \quad(1-2), \quad 55-73 \quad$ (2008) doi:10.1016/j.geomorph.2006.12.024

31. T. Spillmann, H. Maurer, et al., Journal of Geophysical Research-Solid Earth 112 (B7), 25 (2007) doi:10.1029/2006jb004723

32. A. Tibaldi, L. Ferrari, G. Pasquare, Geomorphology 11(3), 215-226 (1995) doi:10.1016/0169-555x(94)00060-5

33. J. Travelletti, P. Sailhac, et al., Hydrological Processes 26 (14), 2106-2119 (2012) doi:10.1002/hyp.7983 